\title{
Autosomal recessive inheritance of hereditary motor and sensory neuropathy with optic atrophy
}

\author{
R M Chalmers, P Riordan-Eva, N W Wood
}

University Department of Clinical Neurology (Neurogenetics

Section)

R M Chalmers

NWWood

Department of Neuro-

Ophthalmology,

National Hospital for

Neurology and

Neurosurgery, Queen

Square, London, UK

P Riordan-Eva

Correspondence to:

Dr R M Chalmers,

Dr R M Chalmers,
University Department of

Clinical Neurology, Institute

of Neurology, Queen Square,

London WCIN 3BG, UK.

Received 22 July 1996

and in revised form

15 October 1996

Accepted 30 October 1996

\begin{abstract}
Three siblings are reported with childhood onset hereditary motor and sensory neuropathy (HMSN) and adult onset optic atrophy. Electrophysiological studies showed an axonal neuropathy and dysfunction of the retinal ganglion cells or optic nerve. The presumed mode of inheritance is autosomal recessive. This is the second family in which autosomal recessive inheritance of HMSN and optic atrophy (HMSN type VI) has been described, and the first in which electrophysiological studies have been reported.
\end{abstract}

\section{$(\mathcal{F}$ Neurol Neurosurg Psychiatry 1997;62:385-387)}

Keywords: hereditary motor and sensory neuropathy; optic atrophy; autosomal recessive inheritance

The syndrome of hereditary motor and sensory neuropathy in association with optic atrophy has been termed HMSN type VI. ${ }^{1}$ There have been reports of sporadic cases of optic atrophy and neuropathy, ${ }^{2-6}$ but familial cases are unusual. ${ }^{7-11}$ Autosomal recessive inheritance of HMSN type VI was suggested in a report in 1937 of two brothers with neuropathy and optic atrophy. ${ }^{10}$ We report three siblings with childhood onset motor and sensory neuropathy who subsequently developed optic atrophy.

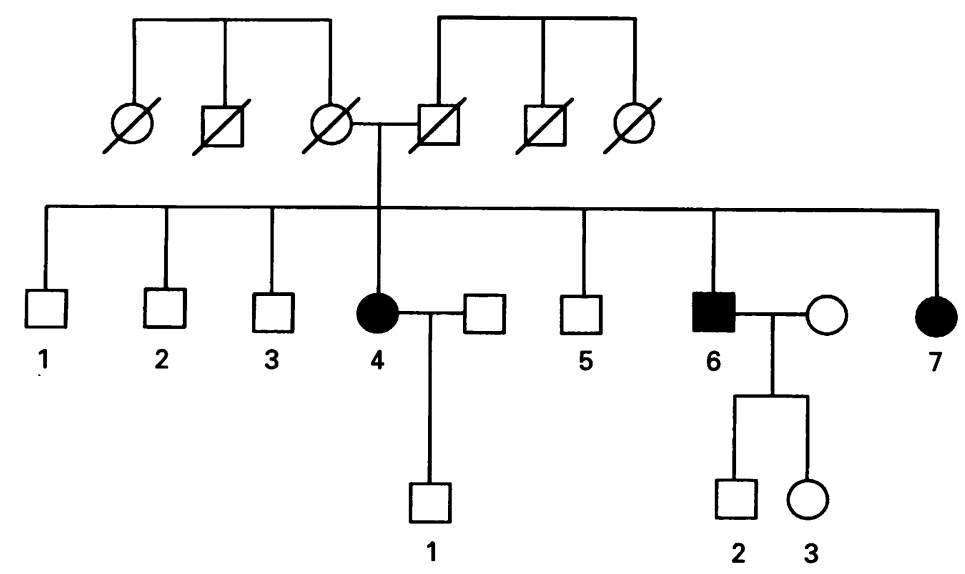

Pedigree of family: solid symbols indicate affected persons.

\section{Case reports}

The figure shows the family pedigree. The family is of Greek Cypriot origin. Three siblings (one man, two women) were affected. Their parents had no neurological complaints and died aged 99 and 85 years. There was no parental consanguinity.

The proband (case II-6), a 57 year old man, developed distal wasting and weakness of the lower limbs when aged 7 years and weakness of the upper limbs when aged 12 years. These problems progressed such that, at the age of 57, he was unable to run, climbed stairs with difficulty, and had weakness of grip. Sensation in all limbs was reduced. Progressive impairment of vision was noted at the age of 47 years and colour vision was abnormal. He had visual acuities of $6 / 9(\mathrm{~N} 12$ at $35 \mathrm{~cm})$ in the left and $6 / 24(\mathrm{~N} 12$ at $20 \mathrm{~cm})$ in the right eye. He was unable to read any of the Ishihara colour plates, other than the test plate, with either eye. Visual fields were constricted with a central scotoma. Fundoscopy showed bilateral optic disc pallor. Cranial nerve examination was otherwise normal. There was no loss of hearing. There was pes cavus and wasting of the intrinsic muscles of the hand and of the distal lower limb muscles, with weakness of the long finger extensors and the intrinsic muscles of the hands and weakness of dorsiflexion and plantar flexion of the feet. He was areflexic with flexor plantar responses. There was glove and stocking sensory loss to all modalities. Romberg's sign was present. Erythrocyte sedimentation rate, plasma glucose, serum electrophoresis, serum vitamin B12, and syphilis serology were normal or negative. Pattern visual evoked potentials (VEPs) were severely attenuated bilaterally; flash VEPs were of anomalous wave form. Pattern electroretinograms from both eyes showed an N95 component reduction, and from the left eye a subnormal P50 and a relative reduction in the focal electroretinogram. Flash electroretinograms showed no abnormality. Sensory action potentials (SAPs) were unrecordable. Motor conduction studies showed absent responses in the common peroneal and posterior tibial nerves; motor action potentials (MAPs) were reduced in the median $(4.7 \mathrm{mV})$ and ulnar $(3.7 \mathrm{mV})$ nerves without significant reduction in motor conduction velocities (mean median MCV $54 \mathrm{~m} / \mathrm{s}$, mean ulnar MCV $48 \mathrm{~m} / \mathrm{s}$ ). 
Optic nerve and chiasm CT was normal. Mitochondrial DNA analysis did not show a pathogenic Leber's hereditary optic neuropathy mutation.

His sister (II-7), a 54 year old woman, developed wasting and weakness of the lower limbs when aged 9 years and weakness of the upper limbs when aged 12. These problems progressed such that, at the age of 54, she could not run, was unable to walk more than 200 yards, and had significant weakness of grip. Sensation was reduced in all limbs. Impaired vision was noted at the age of 50 and progressed. Visual acuities were $6 / 12$ bilaterally and 3/17 Ishihara colour plates could be read with each eye. Visual fields were constricted. There was bilateral optic disc pallor. Cranial nerve examination was otherwise normal; there was no loss of hearing. There was pes cavus and wasting of the intrinsic muscles of the hand and of the distal lower limb muscles. There was weakness of the intrinsic muscles of the hands and pronounced weakness of dorsiflexion and plantar flexion of the feet. She was areflexic with flexor plantar responses. There was glove and stocking sensory loss to all modalities. Romberg's sign was present; her gait was high stepping. Visual evoked potentials were within normal limits and of normal latency. SAPs were unrecordable. Motor conduction studies showed absent responses in the common peroneal and posterior tibial nerves; MAPs were reduced in the median $(0.5 \mathrm{mV})$ and ulnar $(1.8 \mathrm{mV})$ nerves without significant reduction in motor conduction velocities (mean median MCV $39 \mathrm{~m} / \mathrm{s}$, mean ulnar MCV $47 \mathrm{~m} / \mathrm{s}$ ).

The third sibling (II-4), a 62 year old woman, was considered affected on the basis of history provided by relatives. She developed distal wasting and weakness when aged 10 years and had progressive impairment of vision from the age of 50 years.

No other family member had any neurological or ophthalmological complaints. The unaffected siblings were aged between 59 years (case II-5) and 69 years (case II-1). The two children of case II- 6 were normal at neurological and neuro-ophthalmological examination when aged 30 and 36 years.

\section{Discussion}

The three affected siblings in this family developed weakness and sensory loss in childhood and progressive visual failure in adult life. Neurological examination showed a peripheral neuropathy and ophthalmological examination disclosed optic atrophy. Peripheral nerve conduction studies showed an axonal sensorimotor neuropathy; visual evoked potentials and electroretinograms were in keeping with dysfunction of the optic nerves or retinal ganglion cells. Neither their parents nor other family members were affected; their children were beyond the age at which symptoms first developed in affected people. Although a chance association of neuropathy and optic atrophy in these three siblings cannot be excluded, it is likely that they represent autosomal recessive inheritance of HMSN VI.
Autosomal recessive inheritance of neuropathy and optic atrophy has been suggested in two previous reports. In the first, a man was described with childhood onset neuropathy and subsequent subacute visual loss at the age of 19 years, with progression over five weeks from normal vision to considerable visual loss. ${ }^{9}$ This pattern of visual loss is suggestive of Leber's hereditary optic neuropathy. His brother had a neuropathy but did not develop visual failure. It is therefore unlikely that this family represented true HMSN VI. In the second report, two brothers with consanguinous parents were described. ${ }^{10}$ The affected siblings developed both visual impairment and neuropathic weakness in childhood; optic atrophy and neuropathy were found on examination. Although autosomal recessive HMSN VI is the probable diagnosis in this family, $\mathrm{X}$ linked recessive inheritance cannot be excluded. The same family was described six years later, by which time a sister had developed "disseminated sclerosis". ${ }^{12}$ No neurophysiological data were reported from these families.

Optic atrophy and neuropathy have been described in families that show autosomal dominant $^{711}$ and $\mathrm{X}$ linked recessive inheritance. ${ }^{8}$ In addition, there have been reports of sporadic cases of optic atrophy and neuropathy ${ }^{2-6}$; some of these cases may represent autosomal recessive inheritance of HMSN VI. Nerve conduction studies in one sporadic case showed an axonal sensorimotor degeneration. ${ }^{6}$ However, the classification of these reports is complicated by the need to differentiate progressive optic atrophy from other forms, such as Leber's hereditary optic neuropathy. The description of subacute visual loss in young adult men in three of these reports ${ }^{256}$ is suggestive of Leber's hereditary optic neuropathy.

Optic atrophy and neuropathy have also been described in association with other features-in particular, the triad of optic atrophy, neuropathy, and deafness has been reported in families showing autosomal dominant, recessive, and $\mathrm{X}$ linked modes of inheritance. ${ }^{13-15}$

This report is the second description of autosomal recessive inheritance of HMSN type VI and the phenotype in this family differs from that previously described. Electrophysiological studies have not previously been reported and, in this family, showed an axonal sensorimotor neuropathy and evidence of retinal ganglion cell or optic nerve dysfunction. The genetic basis of some autosomal dominant and $\mathrm{X}$ linked forms of $\mathrm{HMSN}^{16}$ and of some families with dominant optic atrophy ${ }^{17}$ has been clarified but the aetiology of HMSN type VI remains unknown.

1 Dyck PJ, Chance P, Lebo R, Carney JA. Hereditary motor and sensory neuropathies. In: Thomas PK, Dyck PJ, eds. Peripheral neuropathy. Philadelphia: Saunders, 1993: 1094-136.

2 Gordon A. Remarks on primary neurotic atrophy (CharcotMarie-Hoffman type) with report of a case in which there was excessive indulgence in tea and coffee. 7 Nerv Ment Dis 1903;30:354-9.

3 Krauss W. Atrophia Nervi optici und Neurotische muskelatrophie. Zeitschrifi fur Augenheilkunde 1916;16:503-16.

4 Piton J. L'amyotrophie Charcot-Marie [MD thesis]. University of Paris: Paris, 1941.

5 Hoyt WF. Charcot-Marie-Tooth disease with primary optic atrophy. Report of a case. Arch Ophthalmol 1960; 64:925-8. 
6 Weiller C, Ferbert A. Hereditary motor and sensory neuropathy (HMSN) and optic atrophy (HMSN Type VI, Vizioli). Eur Arch Psychiatry Clin Neurosci 1991;240: 246-9.

7 Vizioli F. Dell'atrofia progressiva nervosa. Bollettino della $R$ Accademia Medico-Chirurgica di Napoli 1889;1:173-83.

8 Sainton P. L'amyotrophie type Charcot-Marie [MD thesis] University of Paris: Paris, 1899.

9 Ballet G, Rose F. Un cas d'amyotrophie du type CharcotMarie avec atrophie des deux nerfs optiques. Rev Neurol 1904;12:522-4.

10 Schneider DE, Abeles MM. Charcot-Marie-Tooth disease with primary optic atrophy. Report of two cases occurwith primary optic atrophy. Report of two cases

11 Chalmers RM, Bird AC, Harding AE. Autosomal dominant optic atrophy with asymptomatic peripheral nant optic atrophy with asymptomatic peripheral
neuropathy. $f$ Neurol Neurosurg Psychiatry 1996;60: neuropa
$195-6$.
12 Milhorat AT. Studies in diseases of muscle. XIV. Progressive muscular atrophy of peroneal type associated with atrophy of the optic nerves: repor
Neurol Psychiatry 1943;50:279-87.

13 Hagemoser K, Weinstein J, Bresnick G, Nellis R, Kirkpatrick S, Pauli RM. Optic atrophy, hearing loss, and peripheral neuropathy. Am $\mathcal{f}$ Med Genet 1989;33. $61-5$

14 Taylor J. ?Peroneal atrophy. Proc $R$ Soc Med 1913;6:50.

15 Rosenberg RN, Chutorian A. Familial optoacoustic nerve degeneration and polyneuropathy. Neurology 1967;17: 827-32.

16 Harding AE. From the syndrome of Charcot, Marie and Tooth to disorders of peripheral myelin proteins. Brain 1995;118:809-18.

17 Eiberg H, Kjer B, Kjer P, Rosenberg T. Dominant optic atrophy (OPA1) mapped to chromosome $3 \mathrm{q}$ region. I. Linkage analysis. Hum Mol Genet 1994;3:977-80.

\section{HISTORICAL NOTES}

\section{Johann Jakob Wepfer (1620-95) and cerebral haemorrhage}

The Swiss physician Wepfer showed that apoplexy is due to cerebral haemorrhage. In Historiae apoplecticorum, published in $1658,{ }^{1}$ is a detailed description of four cases, his first case having been studied in 1655:

“Johann Jacobus Reiter Kenzinga-Brisgojus, age about 45 years, with a slender build, endowed with yellow and curly hair, naturally strong; of honest parents, descended from the Consul. He acted as schoolmaster and at length was admitted to a most celebrated Monastery. He suffered from extensive gouty arthritis.

In the year 1655 , the seventh day of November . . . he did much of everything-assisted the Most Reverend Lord Abbott in the carrying out of sacraments; (later that day) the Abbott by chance found him prostrate upon the ground, insensible to shouts, to shaking and pinching . . . I was summoned:

I arrived in half an hour, I saw him livid from pallor, deprived of all sensation and animate motion, with nostrils cold to the touch. His pulse at first strong, full, quick, soon afterwards weaker, smaller and more frequent, his breathing also more laborious, soon it became irregular, and many times appeared about to cease from within ... At the tenth hour before midday his body was shaken albeit by a movement and much sputum white, viscid, tenacious passed from his mouth, but indeed no blood: after this more and more his strength began to weaken and his extremities to become more cold; The first hour after midday he ceased to live ...

I opened the head: the skull removed and the dura mater being cut into pieces much blood flowed from the space between this and the thin meninges, copiously ... Nor truly had the blood collected solely at the base of the brain, but covered it all over the top both anteriorly and posteriorly, indeed it had forced itself into nearly all the windings of the brain, as many as there are: extravasated blood totalled two pounds. The whole brain, ventricles and surface were contaminated by blood in large amounts and crumbly; . . . I was able to find no ruptured vein or artery. This however is certain, no external violent cause, be it a blow, be it a fall, was the cause of such ruptures of the blood vessels; to settle this point with his hair cut and skin washed off he showed not the slightest trace of any contusion whatever."
Historiae apoplecticorum also contains "The history of the sickness of Marcello Malpighi, the Pope's physician; with an account of the dissection of his corps".

Wepfer was one of the earliest investigators of the cerebral vasculature. His book on diseases of the head ${ }^{2}$ provided an ample account of basilar artery migraine and its location in the brainstem, a description of a stroke in migraine in a child; and, he wrote of the visual aurae and diagnosis of migraine. He also described trigeminal neuralgia localised to the maxillary nerve.

Born in Schaffhausen, Switzerland in 1620, son of the Councillor of the local Canton, Wepfer read medicine publishing for his degree in $1647 \mathrm{De}$ palpitatione cordis, which stoutly supported Harvey's controversia ideas on the circulation of the blood. He studied in Basle, Strasbourg, and Italy, but returned to his native town where he built a successful practice. His renown spread widely, and his name was hallowed as "The Hippocrates of Helvetia."

A man of temperate habits, he was a most industrious scholar, devoted to reading and the scriptures. His son Johann Conrad and his grandson Georg Michael became physicians. His considerable library and writings were bought by the University of Leyden in 1774 for $\mathbf{4 0 0}$ gold florins.

$$
\begin{array}{r}
\text { JMS PEARCE } \\
304 \text { Beverley Road, } \\
\text { Anlaby, } \\
\text { East Yorks HU10 } 7 B G, U K
\end{array}
$$

1 Wepfer JJ. Historiae apoplecticorum. 1658. English translation from Bagvili's Practice of Physik, London 1704; cited in Major RH. Classic descriptions of disease, 3rd ed, Illinois: Charles C Thomas, 1945:474-7.

2 Wepfer J. Observationes Medico-practicae de Affectibus capitis ... scaphasii. JA Ziegler Schaffenhausen. Obs CVIII, 480: cited by Isler H. In: Blau JN, ed. Migraine London: Chapman and Hall, 1987:665. 